\title{
CELL CULTURE IN THREE-DIMENSIONAL LATTICES OF HYDRATED COLLAGEN FIBRILS - ITS PROGRESS AND PERSPECTIVES
}

\author{
N. SAITO ${ }^{1}$, H. ADACHI ${ }^{2}$, H. TANAKA ${ }^{2}$, S. NAKATA ${ }^{2}$, N. KAWADA ${ }^{1} \&$ K. YOSHIZATO ${ }^{1,3}$ \\ ${ }^{1}$ Department of Hepatology, Osaka City University, Japan. \\ ${ }^{2}$ Nippon Menard Cosmetic Co. Ltd., Japan. \\ ${ }^{3}$ PhoenixBio Co. Ltd., Japan
}

\begin{abstract}
Cell culture methodology has been utilized as a powerful tool to characterize cells with a presupposition that the cells in culture faithfully reproduce their in vivo phenotypes. However, it is generally recognized that the cells cultured currently by the most commonly utilized two-dimensional (2D) monolayer technology exhibit different phenotypes from those in living tissues. Cultivation of cells in three-dimensional (3D) lattices of collagen fibrils (collagen gel culture) has been thought to overcome the shortages of $2 \mathrm{D}$ cell culture such that the cells behave as in vivo by interacting with not only nearby other cells but also by surrounding extracellular matrices. A remarkable outcome of studies on collagen gel culture was a demonstration of contractile nature of the cells. One of the not-fully appreciated issues about the 3D cell culture is the effect of fluid flow through the collagen gels on cells' phenotypes. In this review, we make a short overview of historical and current studies of the collagen gel culture from a viewpoint of 'how we can more correctly extract the cell-related phenomena in living tissues/organs by in vitro culture technology, placing an emphasis on the importance of stimuli caused by flow of cell culture medium.'

Keywords: Collagen gel culture, connective tissue modeling, ECM compositions, gel contraction, interstitial fluid flow, tensile strength.
\end{abstract}

\section{INTRODUCTION}

The understanding of life stands on the fundamental concept (cell theory), an idea proposed by Schleiden [1] and Schwann [2], that the ultimate unit of all living existence is the cell in that there is no life activity when we break down a cell into subcellular entities. In other words, the life is the outcome of cells' individual activities and interactions among cells. Therefore, studies to reveal properties of cells are directly connected to understanding the life itself. Generally, when a scientist is to study a phenomenon of interest, he/she first looks for an experimental setting in which he/she is able to recapitulate the target phenomenon in a manageable way, changing state parameters that affect the nature of a phenomenon. Second, he/she asks what are the basic and simplest entities, without which the phenomenon does not take place. Recapitulation is thought to be a key methodology in understanding a phenomenon. One of the realistic and practical ways of recapitulating a phenomenon generated by cells in living tissues is the in vitro cultivation of the cells separated from a living system under conditions that mimic as closely as possible those of a living tissue.

\section{THREE-DIMENSIONAL VERSUS TWO-DIMENSIONAL CULTURE OF CELLS}

More than a century ago, a cell/tissue culture technology was introduced as a tool to grow nerve fibers by Harrison [3], which is thought to be the origin of cell culture technology. Since then, cells have been generally cultured on the two-dimensional (2D) surface of glass/plastic dishes/plates in which appropriate medium is placed to bathe the cells. However, it had been recognized that the 2D culture is not ideal, because cells' phenotypes therein are generally different from those in living tissues. One obvious reason for this recognition is that cells in living tissues are present in a 3D architecture, but not on the flat surface of substratum.

(C) 2015 WIT Press, www.witpress.com

ISSN: 1755-7437 (paper format), ISSN: 1755-7445 (online), http://www.witpress.com/journals

DOI: 10.2495/DNE-V10-N1-1-9 


\subsection{Collagen as a filler for 3D culture - discovery of contractile nature of fibroblasts}

The cultivation of anchorage-dependent cells requires substrates to which cells attach themselves. Thus, the 3D culture should provide cells with the space filled with topographical substrates, in which cells reside as in vivo, contrasting to the $2 \mathrm{D}$ culture, which just provides them with planer substrates, a completely artificial space. Researchers at the dawn of 3D culture, $~ 40$ years ago, utilized fibroblasts as one type of the cells in their 3D culture studies, which appears to be quite appropriate, because these cells are proper to the connective tissue, the tissue that reach every part of the animal body and, thus, plays fundamental roles to form the body structure. Collagen is the protein specific to the connective tissue and plays roles as substrate for fibroblasts. Importance of the connective tissue in body structuring is inferred by the fact that the collagen comprises $\sim 20 \%$ of body mass and represents $>30 \%$ of the total protein [4]. Gey, a leading researcher at the beginning of $3 \mathrm{D}$ culture, made a fundamental contribution to characterize collagen gels as the topological substrate, although he himself seemed not to make a 3D culture of cells [5]. He cultured a variety of cell types on the surface of reconstituted transparent collagen gels and studied morphology and growth of the cells. Elsdale and Bard published a pioneering report [6], which has been respected as a 'bible' among the followers. The cited authors presented a method to prepare hydrated collagen lattices (HCLs) as collagen gels 'in which the watery millieu is held within a fibrous collagen net mainly by capillary forces' and said that 'HCLs can be employed as both 2D and 3D substrates in cell behavioral studies.' In addition, as reviewed by Eastwood et al. [7], these authors made an important observation about the contraction of HCLs by human fibroblasts [6], which was described as follows: 'The activity of motile cells within a lattice makes a disturbance, causing a gradual collapse of the lattice to a dense, opaque body less than one-tenth of the original size.' To our knowledge, this observation was original in reporting the phenomenon of cell-mediated collagen gel contraction, which has later become a major target of studies on the cell to extracellular matrix (ECM) interactions, although the cited authors just described a phenomenon, but not its mechanistic aspects.

In reality, a study by Bell et al. [8] has been now recognized as the origin that aroused broad interests in 3D collagen gel culture of interstitial cells and made a big contribution to develop this culture system as a useful culture technology not only in basic but also in applied areas of cell research. Fibroblasts were embedded in gels of HCLs containing fetal bovine serum (FBS) and ordinary culture medium. 3D cultures were placed in bacteriological dishes to which anchorage-dependent cells usually adhere poorly. The experimental setting of the cited study was as follows, which has become a standard method of 3D-collagen gel culture among researchers thereafter. The initial cell inoculation density was $2 \times 10^{5}$ to $2 \times 10^{6}$ cells $/ \mathrm{ml}$ of gel [8]. Lattices were made of native collagen fibrils (mainly collagen type 1 extracted from rat tails) in McCoy's 5a medium whose initial concentrations were $\sim 0.2-0.6 \%(\mathrm{w} / \mathrm{v})$, which implies that the original water content of the gel was as high as $>99 \%$. When the fibroblast-populated gels were warmed to $37^{\circ} \mathrm{C}$, the lattices started to be contracted, which accompanied with the exclusion of water from them, and decreased its volume, the extent of which depended on the inoculated cell numbers and the original collagen concentrations. The contraction required the presence of FBS [9] and suppressed when colcemid was included [8], an inhibitor of microtubule organization. Histology showed that the condensed collagen gel had connective tissue (dermis in this case)-like structures, suggesting that fibroblasts had reorganized the collagen fibrils that were initially randomly dispersed at diluted concentrations $(<0.1 \%)$ in the gel composed of monomers of collagen [8]. Therefore, the cited authors thought that the observed fibroblast-induced

collagen condensation represents the tissue (connective tissue in this case) morphogenesis in vivo and they coined the 'dermis-equivalent' for the resulting gel condensate. The discovery of cellmediated collagen condensation brought about general interests in 3D collagen gel culture and 
opened two ways for its usage, one as a tool to study the mechanism of tissue morphogenesis/ organogenesis and the other as a biomaterial for tissue restoration/regeneration. Currently, this collagen gel culture is recognized as an in vitro model that most faithfully mimics the living connective tissue and is commonly utilized as a tool to study the mechanisms of interactions of cells with ECMs in a broad sense.

\subsection{Other 3D fillers as manageable biomaterials by engineering}

The emergence of practically usable 3D culture method also stimulated studies that looked for other appropriate fillers of 3D spaces for cells, especially, in the research area of biomaterials. These fillers can be largely divided into two groups, biological fillers that are derivatives of natural ECMs and those of synthetic polymers [10]. These two types of 3D culture substrates show common features to meet the requirements to be such substrates. These materials can make a liquid phase to solid phase transition depending on atmospheric conditions (usually temperature at neutral $\mathrm{pH}$ ); they are in a state of liquid when researchers prepare cell suspensions in these materials (substrate-cell mixes) and are capable of gelating/solidifying at $37^{\circ} \mathrm{C}$ (culture temperature) to gain a sufficient mechanical strength to be self-supporting and, thus, cells are entrapped within the hydrated gels. These gels at culture temperature are porous for cells' nutrient and waste exchanges. Representative substrates grouped as natural ECMs include collagen type 1 gels as described above, fibrin gels [11], basement membrane gels such as Matrigel ${ }^{\circledR}$ [12] and stromal ECM [13]. Those grouped as synthetic fillers include polyethylene glycol-based hydrogels [14] and self-assembling peptides [15].

\section{FACTORS REQUIRED FOR 3D CULTURING - BASIC CONSTRAINTS FOR RECAPITULATING THE LIVING CONNECTIVE TISSUE BY 3D COLLAGEN GEL CULTURE OF FIBROBLASTS}

The cells in living tissues are thought to take their own morphology and conduct their own functions under physical and biochemical environments specialized for respective cells. These environmental conditions act on the cells as constraints and cause them to survive on the 'way' that has been constructed according to the respective genetic program. Therefore, to mimic living cells in vitro, we have to correctly incorporate these constraints derived from the genetic program as precisely as possible. As mentioned above, 3D collagen gel technology can be used as a reliable in vitro system when we intend to recapitulate the physical, biochemical and biological state of connective tissues in vitro. Thus, issues arise that what constraints should be incorporated into this model of connective tissue. Tissues are complex aggregates of cells and ECMs that are able to only generate and survive under a variety of constraints. Among them, biochemical signals such as growth factors and cytokines have been major targets for studies in cell and molecular biology areas. In this review, focusing on the dermal connective tissue, we make a brief overview for other seemingly important constraints such as ECM compositions and their concentrations, cell density, interstitial fluid flow velocity and tension/ compression that internally generates in tissues. Considerations on these constraints might contribute to design a correct 3D-collagen gel fibroblast culture as a faithful model of living connective tissue.

\subsection{ECMs}

Connective tissues generally provide other tissues (parenchymal tissues) with mechanical supports and frameworks. ECMs are essential substrates as biochemical entities that form a mechanically

bearable tissue framework. Information of ECM contents in the human skin is available in previous studies, and these values are thought to be close to those of the dermis, because the dermis much 


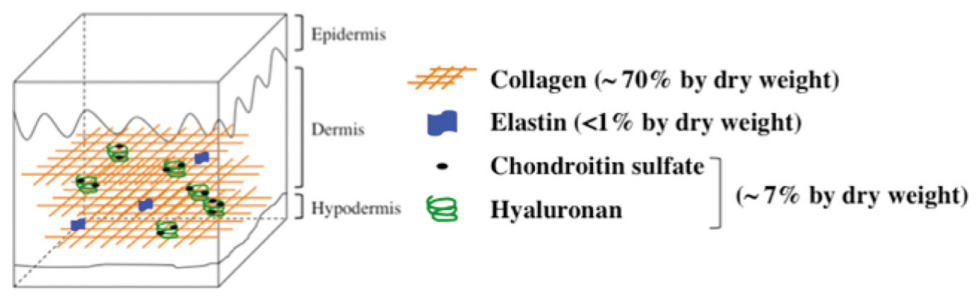

Figure 1: A conceptual illustration of adult human dermal ECM components and their abundance ratios by dry weight basis. Collagen overwhelmingly dominates the other components. Glycosaminoglycans (chondroitin sulfate, mostly chondroitin B, and hyaluronan) are present at the abundance of $\sim 7 \%$.

dominates the epidermis in the ECM deposition. Collagen is the most abundant ECM protein in the skin, occupying $20 \%$ of it by wet weight basis [16] or $~ 70 \%$ by dry weight basis [17] as schematically shown in Fig. 1. Elastin is also a member of the dermis ECM, but its contribution to the formation and function of the connective tissue appears to be much less than that of collagen, because its content being $<1 \%$ by the dry weight basis [18]. The dermis is rich in mucopolysaccharides, $\sim 7 \%$ by dry weight basis [17], consisting of almost equal amounts of chondroitin sulfate and hyaluronan [19]. Hitherto studies have generally been only utilizing collagen type 1 as the ECM substrate in their 3D collagen gel cultures.

\subsection{Fibroblasts density in the dermis}

There was a study that determined fibroblast density in the human dermis [20]. Skin samples were obtained from healthy donors ranging in age from 10 to 25 years, fixed, sectioned, stained with hematoxylin and subjected to image analysis for fibroblasts counting through a microscope. The fibroblasts were distinguished from other types of cells present in the dermis, endothelial cells, lymphocytes and monocytes/macrophages by their nuclear form (elliptical for fibroblasts and rounder for others), their location and by labeling with specific antibodies. As a result, it was found that middermis fibroblast counts ranged from $2.1 \times 10^{3}$ to $4.1 \times 10^{3} / \mathrm{mm}^{3}$. This in situ fibroblasts density is informative in designing a $3 \mathrm{D}$ collagen gel culture as a model of the human dermis.

\subsection{Interstitial fluid flow}

Cells in tissues are generally bathed with interstitial fluid that come out mostly from arterial capillaries and also from the cells themselves therein and get into lymph vessels or in part into venous capillaries. Interstitial flow appears to affect the activities of cells that reside within an in vivo 3D environment. It plays roles not only in cell nourishment but also, for example, in driving fibroblast-associated tissue organization [21]. Utilizing 3D collagen gels for culturing tumor cells, Polacheck et al. demonstrated that interstitial flow influences the direction bias of cell migration, in which CCR7 pathways are involved and that the flow induces phosphorylation of focal adhesion kinase [22].

There was a study that directly measured normal interstitial flow velocity in vivo, using rabbits as a model of animals [23]. Transparent chambers were implanted in their ears. The ear with the chamber was extended and attached to the stage of a microscope and fluorescence-labeled albumin was injected intravenously into the contralateral ear. An appropriate region of the tissue interstitium in the chamber was photobleached by exposure of laser irradiation and monitored for the recovery of 
fluorescence due to interstitial medium flow. The average fluid velocity obtained by this study was $\sim 0.6 \mu \mathrm{m} / \mathrm{s}$. The value could be informative in designing medium-flow 3D cultures fibroblasts.

\subsection{Internal tension/compression in and on fibroblasts and ECM}

It has been thought that tensile forces are principal 'internal factors' that are generated within cells and also within tissues and drive a variety of biological phenomena to proceed such as division and migration at the cell level and morphogenetic events at the tissue level. Especially, it has been well recognized that tensile forces are vital in regulating morphogenesis in embryonic development [24]. In spite of its potential attractiveness and importance, progresses in the study on the mechanical property of cells and tissues have been behind those on the protein/gene-level property due to the lack of appropriate tools to characterize such mechanical properties in the living system. Generally, the studies have been quite limited, which directly measured in vivo tensile strength of living tissues in resting conditions or of the tissues that actively undergoing morphogenesis. However, there were a series of study, which described the mechanical properties of human skin in vivo [25, 26]. This kind of study could provide practically valuable information to us when we design a 3D collagen culture that more appropriately reflects in vivo situation of tensile strength.

It is relevant to emphasize here that the collagen gel culture of fibroblasts is an ideal in vitro model to study internal tensile forces generated by fibroblasts. Figure 2 illustrates fibroblast's contractile force-dependent collagen gel contractions observed in three different types of collagen gel culture. When fibroblast-populated collagen gels were cultured in a siliconized glass dish, gels became freefloating as the contraction proceeded and finally became a floating spheroidal mass (Fig. 2Bg). In a hydrophilic plastic dish, the gel was attached to the dish in its central region, but gradually detached in the peripheral region as the culture proceeded in which the gel was curled up (Fig. 2Bh). A gel in a collagen fibril-coated plastic dish was mostly attached to the dish through the culture period (Fig. 2Bi), which resulted in a robust decrease in its thickness. Thus, the gel in the collagen fibrilcoated dish appears to be loaded with tension force.

As a matter of fact, researchers soon realized that the gel contraction was the overall outcome of tensile forces generated in the cells that are migrating in the collagen gel, driving the cells to draw the attached collagen fibrils toward their tail sides of the migrating [27]. This recognition of 3D collagen gel culture as a model to study a mechanics of cell to ECM interactions has made the model a powerful research tool in the field of mechanobiology [27]. The qualitative and quantitative information of the contractile nature of fibroblasts obtained from 3D collagen gel culture have been a rich and valuable source to evaluate the roles of internal and external tensile strength in living cells and tissues [6].

\section{CONCLUSION}

The $3 \mathrm{D}$ collagen gel culture is thought to have several advantages over conventional $2 \mathrm{D}$ cultures. For example, first, cells are allowed to behave three-dimensionally as in vivo and, secondly, cells can interact with not only cells, but also with ECMs that greatly affect the expression of phenotypes of cells. A representative outcome of the studies using the collagen gel culture was the successful demonstration of the contractility of cells, which is associated with tissue morphogenesis and organogenesis. 3D collagen gel culture modeling of cell to ECM interactions has become a common method to investigate these interactions at the molecular levels. However, researchers have not incorporated vascular-like structures with blood flow into the 3D gel culture, in spite of the general understanding that stresses given to cells by interstitial fluid flow regulate the cells' physiological and pathological activities. Based upon our current experiences of medium-flow collagen gel culture, we are developing a 3D collagen gel culture-based system that can more correctly recapture the phenomena played by cells in living tissues and organs as cartooned in Fig. 3B. 
A

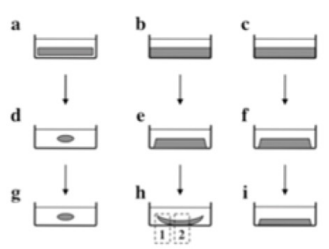

B

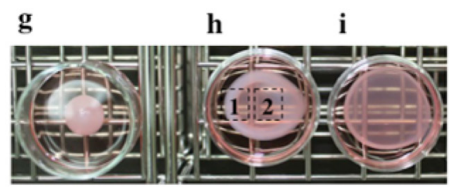

C

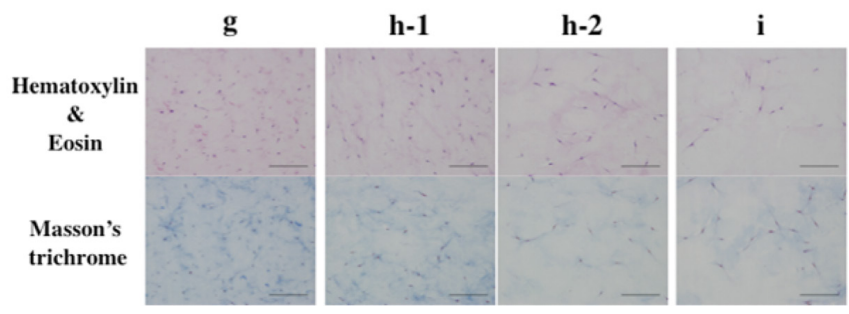

Figure 2: Three types of collagen gel culturing of human fibroblasts. (A) A schematic representation of collagen gel culturing by three different types of dish. Human dermal fibroblasts were suspended at $2 \times 10^{5}$ cells $/ \mathrm{ml}$ of $0.2 \%$ (w/v) collagen sols made in Dulbecco's modified Eagle's medium containing 10\% (v/v) FBS and $3 \mathrm{~mL}$ of the suspensions. Each was placed in a hydrophobic glass dish that had been siliconized (a, d, g), in a hydrophilic plastic culture dish $(\mathrm{b}, \mathrm{c}, \mathrm{h})$ and in a hydrophilic plastic culture dish that had been coated with collagen fibrils (c, f, i). The dish diameter was all $35 \mathrm{~mm}$. These dishes were incubated at $37^{\circ} \mathrm{C}$ in a $5 \% \mathrm{CO}_{2} / 95 \% \mathrm{O}_{2}$ atmosphere during the culture periods. The gel contraction is schematically drawn on day 0 (a, b, c), day $1(\mathrm{~d}, \mathrm{e}, \mathrm{f})$ and day 6 (g, h, i). Due to interactions of migrating fibroblasts with collagen lattices, the gels were contracted and decreased in volume. The gel in the silicon-treated glass dish was detached from the dish surface and became a free-floating gel in a day after incubation. The gel in the plain dish stuck to the dish in early days of culture, but later detached itself from the dish as a free-floating gel as stress-relaxation condition. Most part of the gel in the collagen fibril-coated dish did not detach itself from the dish during culture periods, but its peripheral regions were often detached and curled toward the center of the gel. (B) Macroscopic upper views of collagen gels photographed on day 6. Alphabets $\mathrm{g}, \mathrm{h}$ and $\mathrm{i}$ correspond to those in (A). (C) Histochemical analysis of gels cultured for 6 days by three types of culturing. The gels were fixed for preparation of histological sections. The sections were stained with hematoxylin \& eosin (HE, upper line) or Masson's trichrome (MT, lower line). Alphabets $\mathrm{g}$, $\mathrm{h}$ and $\mathrm{i}$ correspond to those in $\mathrm{B}$. The left-half side of the gel made in the plain dish was divided into two parts, 1 and 2 as shown in B. ' $h-1$ ' and ' $h-2$ ' in $C$ correspond to ' 1 ' and ' 2 ' in the middle (plain) dish in B. The stained specimens were photographed using a microscope. It is evident from the HE photos that cells in the contracted gel, which was not stretched and, thus, under tension-free conditions, were highly concentrated as compared with those in the non-contracted gel, which was stretched and, thus, loaded with tension. MT photos show that collagen fibrils (blue color) in the contracted gel were pulled toward the cell bodies and highly concentrated around the cells as compared with those in the non-contracted gel. Bars represent $200 \mu \mathrm{m}$. 
A

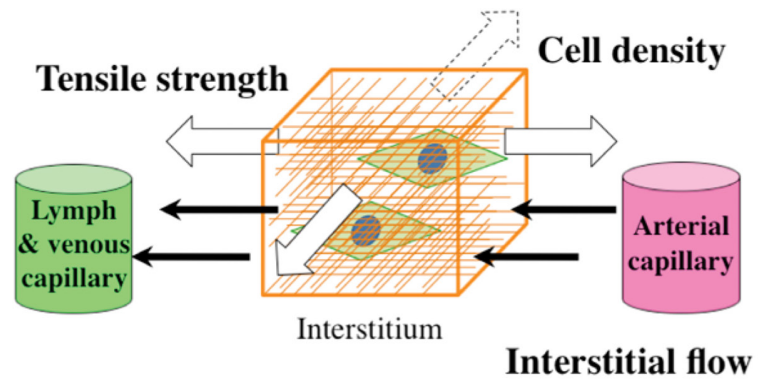

B

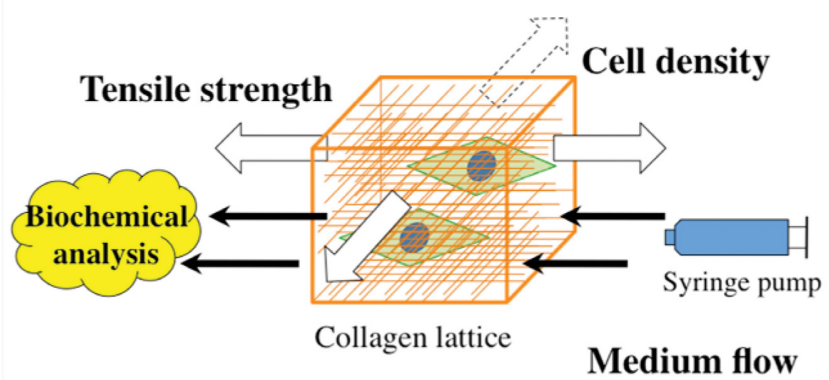

\# Collagen $<$ Fibroblasts

Figure 3: Design of ideal 3D collagen gel culture of fibroblasts. The quantitative and qualitative information regarding in vivo microenvironments in which fibroblasts reside is informative in designing an in vitro model of the dermis utilizing 3D collagen gel culture technology. The in vivo microenvironment of fibroblasts in the dermis is cartooned in $\mathrm{A}$, incorporating information from the published literatures. Fibroblasts in the normal living tissues are continuously exposed to tissue fluid (interstitial fluid), which flows from arterial capillaries to lymph and venous capillaries at the velocity of $\sim 0.1$ to $2 \mu \mathrm{m} / \mathrm{s}[23,28,29]$. The density of fibroblasts in the dermis was reported to be $2.1 \times 10^{3}$ to $4.1 \times 10^{3}$ cells $/ \mathrm{mm}^{3}$ [20]. The interstitium (dermis in our case) is considered to be under tension generated by the tractional force of fibroblasts [8], which was quantified to be $1-7 \times 10^{5} \mathrm{~N} / \mathrm{m}^{2}[25,26]$. The collagen concentration was determined as $\sim 20 \%$ on the wet weigh basis [16]. We are now designing $3 \mathrm{D}$ collagen gel culture as an in vitro model of living dermis incorporating currently known major physical and biological characteristics of the dermis in vivo as cartooned in B. Medium flow is given by sending a medium through a motor-driven syringe at a similar velocity as shown in A. We are also developing a method by which appropriate stresses are given fibroblasts through hydrated lattices of collagen gel. We can obtain an appropriate density of fibroblasts in the gel by adjusting inoculation numbers of fibroblasts, initial collagen concentrations and the extent of collagen gel contraction in the saturation phase of gel culture. Fibroblasts in gels are exposed to both tensile strength and continuously flow of culture medium bearing fresh nutrients and oxygen. The fluid coming out from the gels are collected for biochemical analysis to measure fibroblasts' metabolic activities and differentiationassociated alterations. 


\section{REFERENCES}

[1] Schleiden, M., Beiträge zur Phytogenesis. J. Arch. Anat. Physiol. Wiss. Med., 13, pp. 137-176, 1838.

[2] Schwann, T., Mikroskopische Untersuchungen über die Übereinstimmung in der Struktur und dem Wachstum der Tiere und Pflanzen, Sander'schen Buchhandlung: Berlin, 1839. doi: http:// dx.doi.org/10.1038/086041a0

[3] Harrison, R.G., Observations on the living developing nerve fiber, Anat. Rec., 1(5), pp. 116-128, 1907; Proc. Soc. Exp. Biol. Med., 4(1), pp. 140-143, 1907. doi: http://dx.doi. org/10.1002/ar.1090010503

[4] Di Lullo, G.A., Sweeney, S.M., Korkko, J., Ala-Kokko, L. \& San Antonio, J.D., Mapping the ligand-binding sites and disease-associated mutations on the most abundant protein in the human, type I collagen. J. Biol. Chem., 277(6), pp. 4223-4231, 2002. doi: http://dx.doi. org/10.1074/jbc.m110709200

[5] Ehrmann, R.L. \& Gey, G.O., The growth of cells on a transparent gel of reconstituted rat-tail collagen. J. Natl. Cancer Inst., 16(6), pp. 1375-1403, 1956.

[6] Elsdale, T. \& Bard, J., Collagen substrata for studies on cell behavior. J. Cell Biol., 54(3), pp. 626-637, 1972. doi: http://dx.doi.org/10.1083/jcb.54.3.626

[7] Eastwood, M., McGrouther, D.A. \& Brown, R.A., Fibroblast responses to mechanical forces. Proc. Inst. Mech. Eng. H., 212(2), pp. 85-92, 1998, Review. doi: http://dx.doi. org/10.1243/0954411981533854

[8] Bell, E., Ivarsson, B. \& Merrill, C., Production of a tissue-like structure by contraction of collagen lattices by human fibroblasts of different proliferative potential in vitro. Proc. Natl. Acad. Sci. USA, 76(3), pp. 1274-1278, 1979. doi: http://dx.doi.org/10.1073/pnas.76.3.1274

[9] Steinberg, B.M., Smith, K., Colozzo, M. \& Pollack, R., Establishment and transformation diminish the ability of fibroblasts to contract a native collagen gel. J. Cell Biol., 87(1), pp. 304-308, 1980. doi: http://dx.doi.org/10.1083/jcb.87.1.304

[10] Baker, B.M. \& Chen, C.S., Deconstructing the third dimension: how 3D culture microenvironments alter cellular cues. J. Cell Sci., 125(13), pp. 3015-3024, 2012, Review. doi: http://dx.doi. org/10.1242/jcs.079509

[11] Ahmed, T.A., Dare, E.V. \& Hincke, M., Fibrin: a versatile scaffold for tissue engineering applications. Tissue Eng. B Rev., 14(2), pp. 199-215, 2008, Review. doi: http://dx.doi.org/10.1089/ ten.teb.2007.0435

[12] Kleinman, H.K. \& Martin, G.R., Matrigel: basement membrane matrix with biological activity. Semin. Cancer Biol., 15(5), pp. 378-386, 2005, Review. doi: http://dx.doi.org/10.1016/j. semcancer.2005.05.004

[13] Beacham, D.A., Amatangelo, M.D. \& Cukierman, E., Preparation of extracellular matrices produced by cultured and primary fibroblasts. Curr. Protoc. Cell Biol., Chapter 10, unit 10.9, 2007. doi: http://dx.doi.org/10.1002/0471143030.cb1009s33

[14] Kloxin, A.M., Kloxin, C.J., Bowman, C.N. \& Anseth, K.S., Mechanical properties of cellularly responsive hydrogels and their experimental determination. Adv. Mater., 22(31), pp. 3484 3494, 2010 (review). doi: http://dx.doi.org/10.1002/adma.200904179

[15] Kisiday, J., Jin, M., Kurz, B., Hung, H., Semino, C., Zhang, S. \& Grodzinsky, A.J., Self-assembling peptide hydrogel fosters chondrocyte extracellular matrix production and cell division: implications for cartilage tissue repair. Proc. Natl. Acad. Sci. USA, 99(15), pp. 9996-10001, 2002. doi: http://dx.doi.org/10.1073/pnas.142309999

[16] Bartley, W., Birt, L.M. \& Banks, P., The Biochemistry of the Tissue. John Wiley \& Sons: London, p. 227, 1968. 
[17] Chvapil, M., Physiology of Connective Tissue, Butterworth: London, p. 62, 66, 70, 1971.

[18] Ryhanen., L. \& Uitto., J., Elastic fibers of the connective tissue. Biochemistry and Physiology of the Skin, ed. L.A. Goldsmith, Oxford University Press: New York, pp. 433-447, 1983.

[19] Watson, E.M. \& Pearce, R.H., The biochemistry of the skin; a review; with particular reference to the mucopolysaccharides. Br. J. Dermatol. Syph., 59(10), pp. 327-333, 1947. doi: http:// dx.doi.org/10.1111/j.1365-2133.1947.tb10870.x

[20] Miller, C.C., Godeau, G., Lebreton-DeCoster, C., Desmoulière, A., Pellat, B., Dubertret, L. \& Coulomb, B., Validation of a morphometric method for evaluating fibroblast numbers in normal and pathologic tissues. Exp. Dermatol., 12(4), pp. 403-411, 2003. doi: http://dx.doi. org/10.1034/j.1600-0625.2003.00023.x

[21] Ng, C.P., \& Swartz, M.A., Fibroblast alignment under interstitial fluid flow using a novel 3-D tissue culture model. Am. J. Physiol. Heart Circ. Physiol., 284(5), pp. 1771-1777, 2003.

[22] Polacheck, W.J., Charest, J.L. \& Kamm, R.D., Interstitial flow influences direction of tumor cell migration through competing mechanisms. Proc. Natl. Acad. Sci. USA, 108(27), pp. 11115-11120, 2011. doi: http://dx.doi.org/10.1073/pnas.1103581108

[23] Chary, S.R. \& Jain, R.K., Direct measurement of interstitial convection and diffusion of albumin in normal and neoplastic tissues by fluorescence photobleaching. Proc. Natl. Acad. Sci. USA, 86(14), pp. 5385-5389, 1989. doi: http://dx.doi.org/10.1073/pnas.86.14.5385

[24] Krieg, M., Arboleda-Estudillo, Y., Puech, P.H., Käfer, J., Graner, F., Müller, D.J. \& Heisenberg, C.P., Tensile forces govern germ-layer organization in zebrafish. Nat. Cell Biol., 10(4), pp. 429-436, 2008. doi: http://dx.doi.org/10.1038/ncb1705

[25] Manschot, J.F. \& Brakkee, A.J., The measurement and modelling of the mechanical properties of human skin in vivo. I. The measurement. J. Biomech., 19(7), pp. 511-515, 1986. doi: http:// dx.doi.org/10.1016/0021-9290(86)90124-7

[26] Manschot, J.F. \& Brakkee, A.J., The measurement and modelling of the mechanical properties of human skin in vivo. II. The model. J. Biomech., 19(7), pp. 517-521, 1986. doi: http://dx.doi. org/10.1016/0021-9290(86)90125-9

[27] Eyckmans, J., Boudou, T., Yu, X. \& Chen C.S., A Hitchhiker's guide to mechanobiology. Dev. Cell, 21(1), pp. 35-47, 2011. doi: http://dx.doi.org/10.1016/j.devcel.2011.06.015

[28] Dafni, H., Israely, T., Bhujwalla, Z.M., Benjamin, L.E. \& Neeman, M., Overexpression of vascular endothelial growth factor 165 drives peritumor interstitial convection and induces lymphatic drain: magnetic resonance imaging, confocal microscopy, and histological tracking of triple-labeled albumin. Cancer Res., 62(22), pp. 6731-6739, 2002.

[29] Harrell, M.I., Iritani, B.M. \& Ruddell, A., Tumor-induced sentinel lymph node lymphangiogenesis and increased lymph flow precede melanoma metastasis. Am. J. Pathol., 170(2), pp. 774-786, 2007. doi: http://dx.doi.org/10.2353/ajpath.2007.060761 